American J. of Engineering and Applied Sciences 1 (4): 248-251, 2008

ISSN 1941-7020

(C) 2008 Science Publications

\title{
Multistage Development of Müller-Achenbach model for Shape Memory Alloy
}

\author{
${ }^{1}$ Simin Ataollahi Oshkovr, ${ }^{1}$ Nik Abdullah Nik Mohamed, ${ }^{1}$ Che Husna Azhari, \\ ${ }^{2}$ Siavash Talebi Taher and ${ }^{2}$ Azim Ataollahi Oshkour \\ ${ }^{1}$ Department of Mechanical and Materials Engineering, University Kebangsaan Malaysia (UKM), \\ P.O. Box 43600, Bangi, UKM, Malaysia \\ ${ }^{2}$ Faculty of Engineering, University Putra Malaysia, Serdang, Selangor, Malaysia
}

\begin{abstract}
This research focused on the conceptual development of constitutive Müller-Achenbach model and proceeds to construct a model based on phase transition under changing temperature and load for variants of martensite in shape memory alloy CuAlNi (Copper-aluminum-nickel). Problem statement: Motivation of this research is rare information of a variant of martensite phase $\left(\mathrm{M}_{++}\right)$and prediction of the shape recovery of shape memory alloy in this stage of transformation. Approach: The mathematical equations proposed a prediction of stability of Austenite phases and extend it to multistage martensitic phase transformation. These phase transformations occurred by loading on the material. Equations described free energy landscape in CuAlNi shape memory alloys at low (260K) and high temperature (440K). The model evaluated the free energy due to the phase transformation between the austenite and multistage martensitic structures. Results: Results for $\mathrm{M}_{++}$phase showed decrease in temperature from $440 \mathrm{~K}$ to $260 \mathrm{~K}$ presented decrease in stress approximately from $1 \mathrm{kN}$ to $0.4 \mathrm{kN}$ and free energy from $5 \mathrm{~kJ} / \mathrm{kg}$ to $0.1 \mathrm{~kJ} / \mathrm{kg}$. Equations have been solved and plotted by software programmed in MATLAB. Conclusions/Recommendations: The model which has derived focused on homogeneous shape memory alloys, but future performance requirements will most likely be met with heterogeneous materials. Therefore, simulation models for heterogeneous materials must be developed.
\end{abstract}

Key words: Phase transformation, martensitic transformation, shape memory alloys

\section{INTRODUCTION}

Shape Memory Alloys (SMAs) are used in a wide range of applications as actuators, biomedical stents, artificial muscles for microrobots, etc., ${ }^{[1]}$. In the medical field, superelastic devices such as eyeglass frames have come to market in the recent years. These alloys are capable of very large recoverable inelastic strain (of the order of $(10 \%)$ ). For this property they have been extensively investigated over the past three decades as potential control materials. The source of the distinctive mechanical behaviour of these materials is a crystalline phase transformation between a high symmetry, highly ordered parent phase (austenite) and a low symmetry, less ordered product phase (martensite) $)^{[2]}$.

Shape-memory alloys derive their interesting properties as a result of a martensitic phase transformation between a high-temperature austenite and a low-temperature martensite phase. This transformation can also be induced by stress above the transformation temperature ${ }^{[3]}$. Martensite is composed of several variants as some scientists identified the martensitic phases $\gamma_{1}^{\prime}, \beta^{\prime}, \beta^{\prime}{ }_{1}$ and $\alpha_{1}^{\prime}$ they proposed that these phases differ by a different crystallographic stacking sequence and denoted the twins of $\gamma_{1}{ }_{1}$ as $M_{\text {. }}$ and $\mathrm{M}_{+}$while $\beta^{\prime}{ }_{1}$ is denoted by $\mathrm{M}_{++}{ }^{[4]}$.

This research analysed multistage martensitic phase transformation in shape memory alloy and predict the deformation of material base on load.

\section{MATERIALS AND METHODS}

This research focused on CuAlNi shape memory alloy and investigated the result in high $(440 \mathrm{~K})$ and low temperature $(260 \mathrm{~K})$. The results were obtained, presented by using especially written software programmed in MATLAB.

Mathematical model: Problem is finding simple and appropriate dissipative mechanisms to be included in the constitutive description of the materials such that

Corresponding Author: Simin Ataollahi Oshkovr, Department of Mechanical and Materials Engineering, University Kebangsaan Malaysia (UKM), PO Box 43600, Bangi, UKM, Malaysia Tel: (+60)123962674 


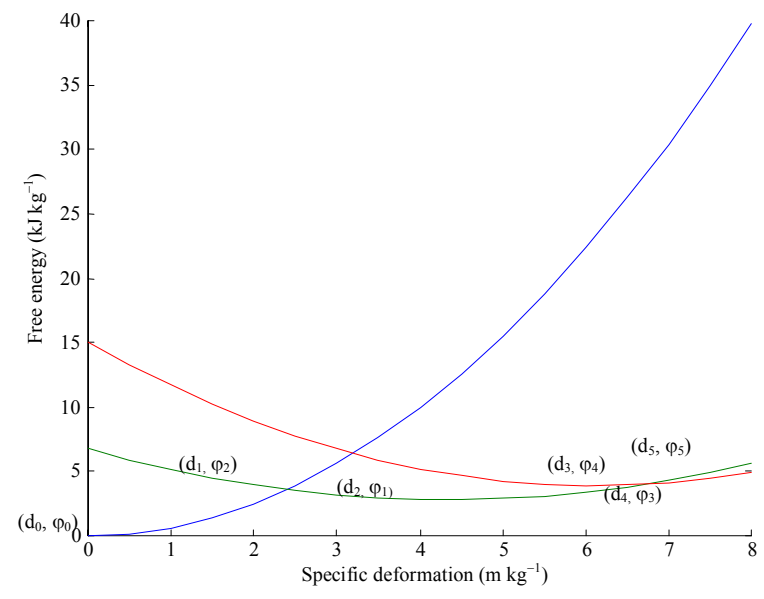

Fig. 1: Non-convex free energy landscapes at high temperature

the model is able to describe the process of phase transformation. In this study the non-convex free energy and non-monotone load-deformation has been investigated. The energy landscape can be constructed as shown in Fig. 1.

General parabola equations for three parabolas in Fig.1 are:

$$
\begin{aligned}
& \varphi_{A}(D)=a_{A} d^{2}+C_{A} 0 \leq d \leq d_{1} \\
& \varphi_{M+}(d)=a_{M+} d^{2}+b_{M+} d+C_{M_{+}} d_{1} \leq d \leq d_{3} \\
& \varphi_{M++}(d)=a_{M++} d^{2}+b_{M++} d+C_{M++} d_{3} \leq d \leq \infty
\end{aligned}
$$

Before the further mathematical solution they have been made shorter by introducing some symbols to make the equations easy to understanding:

$$
\begin{aligned}
& \varphi_{\mathrm{M}+}=\varphi_{+} \\
& \varphi_{\mathrm{M}++}=\varphi_{2+} \\
& \mathrm{b}_{\mathrm{M}+}=\mathrm{b}_{+} \\
& \mathrm{b}_{\mathrm{M} 2+}=\mathrm{b}_{2+} \\
& \mathrm{C}_{\mathrm{M}+}=\mathrm{C}_{+} \\
& \mathrm{C}_{\mathrm{M}++}=\mathrm{C}_{2+}
\end{aligned}
$$

The simplified equations for phases $\mathrm{A}, \mathrm{M}_{+}$and $\mathrm{M}_{2+}$ are:

For A phase:

$$
\begin{aligned}
& \varphi_{A}(d)=\left(\frac{\varphi_{2}}{d_{1}^{2}}\right) d^{2} \\
& \sigma=\frac{\partial \varphi_{A}(d)}{\partial d}=2 d\left(\frac{\varphi_{2}}{d_{1}^{2}}\right)
\end{aligned}
$$

For $\mathrm{M}_{+}$phase:

$$
\begin{aligned}
& \varphi_{+}=\mathrm{Gd}^{2}-2 \mathrm{Gd}_{2} \mathrm{~d}+\mathrm{Gd}_{2}^{2}+\varphi_{1} \\
& \sigma=\left(\frac{\partial \varphi_{+}(\mathrm{d})}{\partial \mathrm{d}}\right)=2 \mathrm{dG}-2 \mathrm{~d}_{2} \mathrm{G}
\end{aligned}
$$

For $\mathrm{M}_{2+}$ phase:

$$
\begin{aligned}
& \varphi_{2+}(\mathrm{d})=\mathrm{Id}^{2}-2 \mathrm{Id}_{4} \mathrm{~d}+\mathrm{Id}_{4}+\varphi_{3} \\
& \sigma_{2+}=\left(\frac{\partial \varphi_{2+}(\mathrm{d})}{\partial \mathrm{d}}\right)=2 \mathrm{dI}-2 \mathrm{Id}_{4}
\end{aligned}
$$

These equations are evaluated at both low and high temperatures.

\section{RESULTS}

Determination of free energy at low temperature: The result obtained for the determination of free energy at low temperature shows the lower parabolas representing as shown in Fig. 2 the specific free energy of different martensitic structures $\left(\mathrm{M}_{+}\right.$and $\left.\mathrm{M}_{++}\right)$. The upper parabola in Fig. 2 is the austenite phase (A) which has a high amount of free energy.

Determination of free energy at high temperature: The results of the determination of free energy landscape at high temperature, is shown in Fig. 3. The lowest parabola, exhibits specific free energy of austenite phase and two other upper parabolas show variant martensitic structures namely $\mathrm{M}_{+}$and $\mathrm{M}_{++}$.

Determination of load at high temperature: Figure 4 shows the phase equilibrium in load-deformation diagram which has been derived mathematically at high 


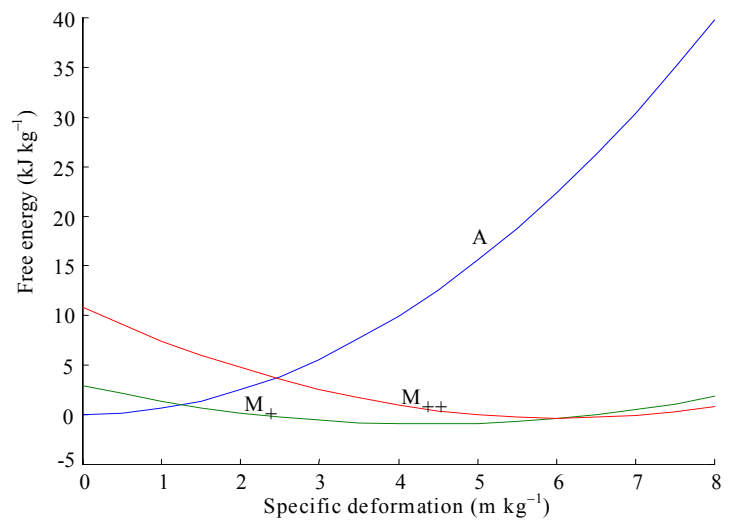

Fig. 2: Free energy landscapes at $\mathrm{T}=260 \mathrm{~K}$ (low temperature)

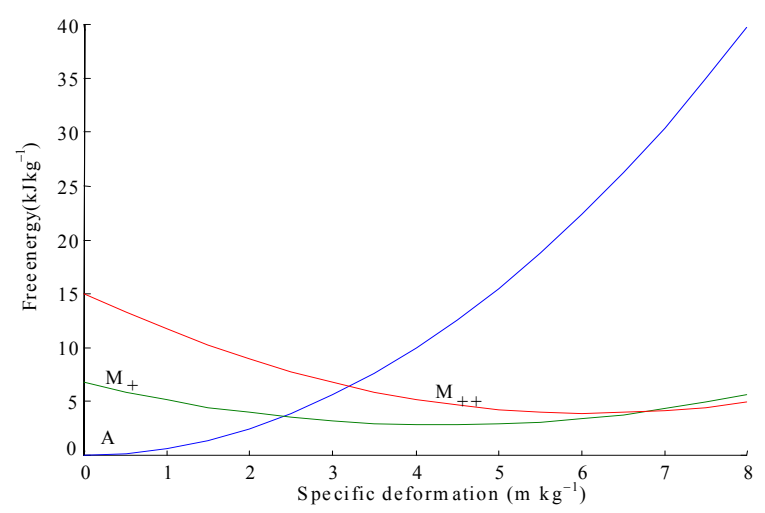

Fig. 3: Free energy landscapes at $\mathrm{T}=440 \mathrm{~K}$ (high temperature)

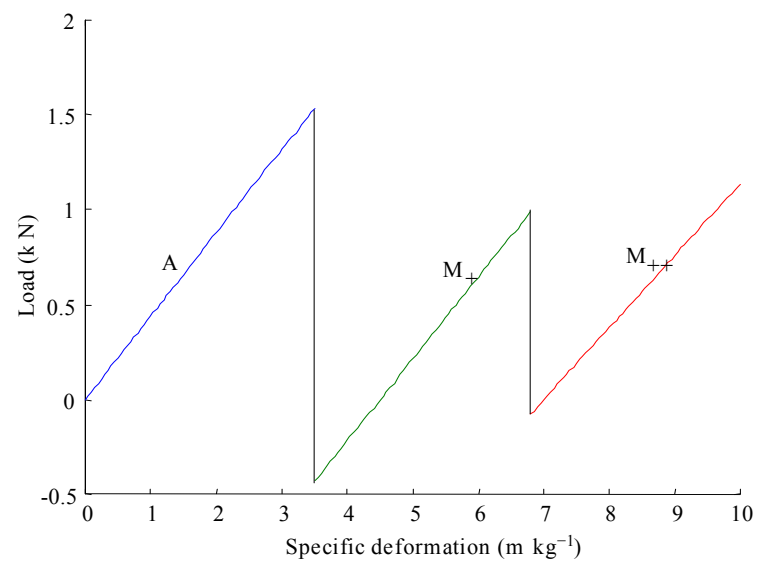

Fig. 4: The construction of phase equilibrium at $\mathrm{T}=$ $440 \mathrm{~K}$ (high temperature)

temperature which presents the behavior of austenite phase and two other variants of the martensite phases.

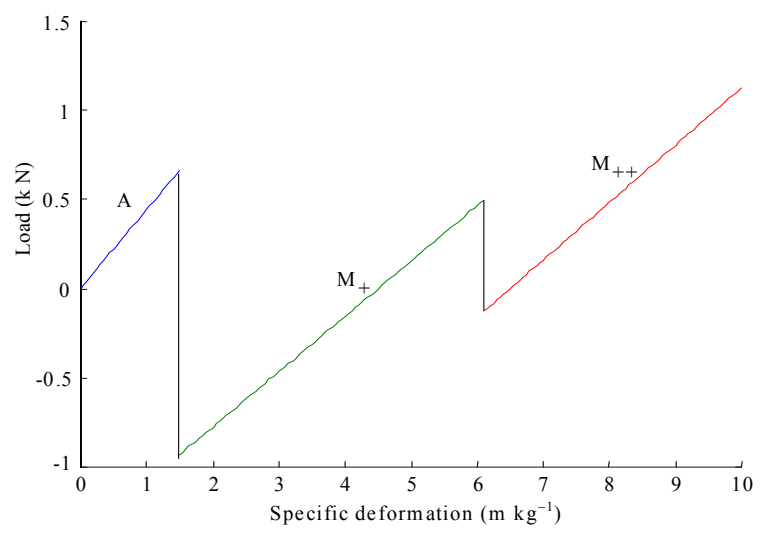

Fig. 5: The construction of phase equilibrium at $\mathrm{T}=$ $260 \mathrm{~K}$ (low temperature)

Increase in deformation and load was obtained at high temperature. This load-deformation figure gives simple landscape of phase transition in the CuAlNi.

Determination of load at low temperature: Figure 5 shows the phase equilibrium in load-deformation diagram at low temperature which presents the behavior of 3 phases. Decreasing deformation and load was obtained at low temperature. It has been shown also the stability of $\mathrm{M}_{+}$at low temperature.

\section{DISCUSSION}

Thermoelastic martensites are characterized by their low energy and interfaces, which can be driven by small temperature or stress changes. As a consequence of this and of the constraint due to the loss of symmetry during transformation, thermoelastic martensites are crystallographically reversible. This gives it the ability to return to the original shape after heating. In the other hand from thermodynamic point of view, at equilibrium, material attempts to minimize the free energy. According to the Helmholtz free energy $F=U-$ TS at low temperature, the second term due to the temperature has little influence and internal energy attempts to be minimal so the free energy becomes minimum. At low temperature, the free energy is identical to the internal energy hence the martensite is stable since it has the deeper potential. The martensite is easily deformed to several percent strains at quite low stress, whereas the austenite (high temperature phase) exhibits much higher yield and stresses ${ }^{[5]}$.

According to the competition between energy and entropy in equilibrium energy attempts to be minimal by assembling all layers in the depths of their potential wells and the entropy attempts to be as big as possible 
by creating an energy equal distribution. At high temperatures, the first term is negligible compared to the second, the free energy becomes minimum, because $\mathrm{S}$ has a higher value. The minimum potential of the austenite phase, rise more slowly with increase in temperature of the martensitic minimum. So when the temperature increases, the austenite phase becomes stable as it has the smaller free energy ${ }^{[5]}$. The relevant effective potential energy is given by the Helmholtz free energy. These are non-convex functions with potential wells corresponding to each phase. Due to the transformation between martensite to austenite phase, the material has the ability to recover all of its deformations on heating. Thus when the temperature is raised above the transformation temperature, low value of free energy at high temperature stabilizes condition for austenite phase and material reverts to austenite phase with a high symmetrical structure. When the external temperature or stress condition changes, austenite and martensite phase will transform to each other, depending on what change appears.

When the temperature is increased again above Af, the martensite gradually transforms back to austenite with the original crystallographic orientation, thus allowing for a full recovery of the detwinning strain ${ }^{[2]}$. Martensite phase is the relatively soft and easily deformed phase of shape memory alloys ${ }^{[6]}$.

\section{CONCLUSION}

This current model followed Müller and Achenbach model to model the second stage of martensite phase. It evaluated free energy and load during phase transition at high temperature and low temperature. The results obtained in this work showed the free energy was postulated as a non-convex function. This approach, upon changing the temperature, dedicated zig-zag behaviour by straight lines in the load-deformation diagram. The advantages presented in this model are prediction the behaviour of the material in all temperatures. Hence decrease the temperature resulted decrease in amount of free energy and stress in shape memory alloy.

\section{REFRENCES}

1. Zaki, W. and Z. Moumni, 2007. A 3D model of the cyclic thermomechanical behaviour of shape memory alloys. J. Mechanics Phys. Solids, 55: 2427-2454, Doi: 10.1016/j.jmps.2007.03.011

2. Brocca, M., L.C. Brinson and Z.P. Bazant, 2002. Three dimensional constitutive models for shape memory alloys based on microplane model. Mechanics Phys. Solids, 50: 1051-1077. Doi: 10.1016/S0022-5096(01)00112-0

3. Bhattacharya, K. and A. Schlomerkemper, 2004. Transformation Yield Surface of Shape-Memory Alloys. J. Phys., 115: 155-162. Doi: 10.1051/jp4:2004115020

4. Abdullah, N., O. Kastner, I. Müller, A. Musolff, H. $\mathrm{Xu}, \mathrm{G}$. Zak, 2002. Observation on CuAlNi single crystals. Non-Linear Mechanics, 37: 1263-1274. Doi: 10.1016/S0020-7462(02)00018-5

5. Müller I. and S. Seelecke, 2001. Thermodynamic aspects of shape memory alloys. Math. Comput. Model., 34: 1307-1355. Doi: 10.1016/S08957177(01)00134-0

6. Bhattacharyya, A., 2001. SMA/MEMS research group (online) http://www.cs.ualberta.ca/ $\sim$ database/MEMS/ sma_mems/sma.html 